\title{
Laser Techniques on Acoustically Levitated Droplets
}

\author{
Antonio Cannuli ${ }^{1,{ }^{*}}$, Maria Teresa Caccamo $^{1}$, Giuseppe Castorina ${ }^{1}$, Franco Colombo $^{1,2}$ and Salvatore Magazù ${ }^{1}$ \\ ${ }^{1}$ Department of Mathematical and Informatics Sciences, Physical Sciences and Earth Sciences, Messina University, Viale F. Stagno \\ D’Alcontres 31, 98166 Messina, Italy \\ ${ }^{2}$ Italian Air Force Meteorological Service, Comando Aeroporto, Sigonella, Catania, Italy
}

\begin{abstract}
This work reports the results of an experimental study where laser techniques are applied to acoustically levitated droplets of trehalose aqueous solutions in order to perform spectroscopic analyses as a function of concentration and to test the theoretical diameter law. The study of such systems is important in order to better understand the behaviour of trehalose-synthesizing extremophiles that live in extreme environments. In particular, it will be shown how acoustic levitation, combined with optical spectroscopic instruments allows to explore a wide concentration range and to test the validity of the diameter law as a function of levitation lag time, i.e. the $\mathrm{D}^{2} \mathrm{vs} t$ law. On this purpose a direct diameter monitoring by a video camera and a laser pointer was first performed; then the diameter was also evaluated by an indirect measure through an $\mathrm{OH} / \mathrm{CH}$ band area ratio analysis of collected Raman and Infrared spectra. It clearly emerges that $\mathrm{D}^{2}$ vs $\mathrm{t}$ follows a linear trend for about 20 minutes, reaching then a plateau at longer time. This result shows how trehalose is able to avoid total water evaporation, this property being essential for the surviving of organisms under extreme environmental conditions.
\end{abstract}

\section{Introduction}

Laser techniques are largely employed on modern spectroscopic instruments. Due to their enormous potentials in terms of optical power, wavelength tenability, time and spatial coherence, narrow line-width, peak power and ultra-short pulse generation, the field of spectroscopy has been deeply widened from the introduction of lasers. Several laser sources can be employed in Raman and Infrared (IR) spectroscopies, such as fixed-wavelength solid-state lasers with relatively high power, ensuring an access to very wide wavelength regions. These spectroscopic techniques are largely employed for probing samples in order to get information on the structural and dynamical properties of substances. They have several advantages, such as easeof-use, minimal preparation of samples and quick realization of spectra (in real time and in situ) [1-5]. In particular, Raman scattering occurs when there is an energy shift in frequency among the incident photons and the vibrational energy levels of the molecule, and in many cases, the magnitude of this shift is the same as that of IR adsorption; though some vibrational modes occur only in the Raman spectrum and vice versa. The differences between Raman and IR are also connected to the molecule symmetry, in fact, more symmetric is the molecule, greater will be the differences between the two spectra. An example is the study of chainlike disaccharide molecules, in which the vibrations of the carbon chain are easily analysed by using Raman spectroscopy, while the vibrations of the side groups can be characterized by using IR spectroscopy. These techniques can be applied in conjunction with levitation methods for the analysis of high concentration samples or when it is necessary to avoid heterogeneous nucleation [6-13]. Droplet free flotation has in fact the advantage of avoiding disturbs due to solid walls around the sample, increasing detection sensitivity. Different techniques for sample levitation have been previously developed and are employed in a variety of applications [14-25]. These include optical electro-magnetic, electrostatic gas-film aerodynamic and acoustic levitation [26-30]. Acoustic levitation combines biological compatibility with stable sample position and easy access to the sample, without requiring any specific physical properties (e.g. electric charge or a certain refractive index) for the sample. In order to benefit from the employ of acoustically levitated droplets, sensitive, remote and non-invasive detection analyses methods are necessary [31-42]. Acoustic levitation also allows to get high concentration samples starting from diluted solutions. In particular, the technique can furnish precious information on hydrogen-bonded systems of biophysical interest, such as, for example, aqueous solutions disaccharides proteins polymers and polyols [43-58]. For these systems, it is extremely important to address the experimental studies to the whole concentration range, starting from highly diluted to highly concentrated solutions [59-69].

In the present work the findings of an experimental study, where laser techniques are applied to acoustically levitated droplets in order to perform spectroscopic analyses are presented [70-75]. The investigated samples are trehalose aqueous solution, synthesized by

* Corresponding author: acannuli@unime.it 
extremophiles that live in extreme environments. Furthermore the $\mathrm{D}^{2}$ versus time law, for the droplet diameter, is tested by means of a direct monitoring performed by a video camera and by means of an indirect measure based on the analysis of the $\mathrm{OH} / \mathrm{CH}$ band area ratio.

It will be shown that acoustic levitation, combined with optical spectroscopic techniques, allows to explore a wide concentration range and to test the validity of the diameter law as a function of levitation lag time, i.e. the $D^{2}$ vs $t$ law. It clearly emerges that $D^{2}$ vs $t$ follows a linear trend for about 20 minutes, reaching then a plateau at longer times. This result shows that by increasing disaccharide concentration the water evaporation is more and more reduced, this property being essential for the surviving of organisms under extreme environmental conditions.

\section{Experimental section}

Aqueous solutions of trehalose, purchased from AldrichChemie, were investigated at different concentration values. The solutions were prepared using doubly distilled water. At first, drops of aqueous solutions of trehalose (of $1.50 \mathrm{~mm}$ of mean radius) were introduced into the acoustic levitator by means of a micropipette injection and the drop diameter decreased as a function of the time. In order to investigate the drying process of aqueous solutions of trehalose, Raman and Infrared data were collected. In particular a HORIBA Jobin-Yvon T64000 spectrometer was employed to collect Raman spectra at $\mathrm{T}=25^{\circ} \mathrm{C}$; for the IR spectra, a FTIR Vertex $70 \mathrm{~V}$ by Bruker Optics spectrometer was employed, to collect absorption spectra under vacuum, at $\mathrm{T}=25^{\circ} \mathrm{C}$.

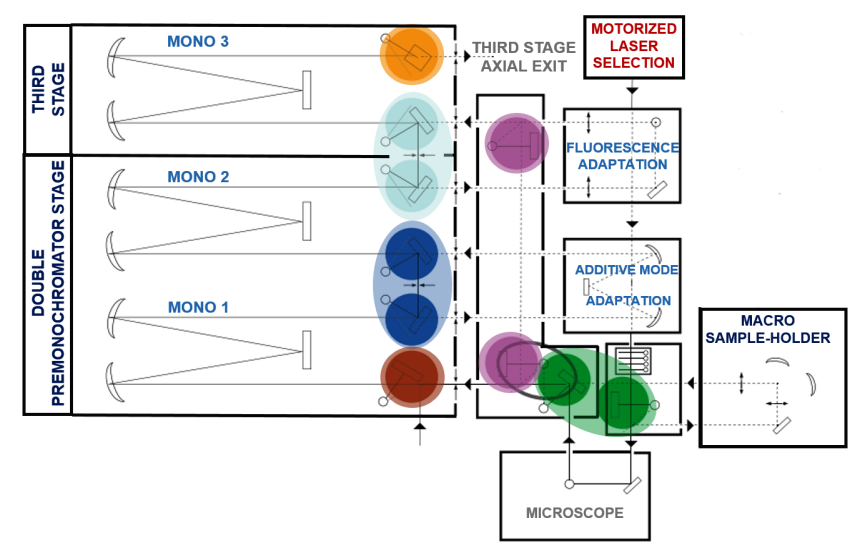

Fig. 1. Scheme of laser beam path in a Horiba Jobin-Yvon T64000 Raman spectrometer from source to detectors. Green section $=$ micro/macro setup; violet section $=$ triple/single configuration; brown section = lateral/axial entrance; blue section $=$ additive/subtractive mode; light blue section $=$ double monochromator-third stage entrance; orange section = axial/vertical exit.

Both Raman and IR spectra are affected by random noise and to reduce the spectral noise a wavelet analysis was performed using thresholding estimators by means of Matlab (R2016a, The MathWorks, Inc. Natick, MA, USA) [77-82]. A Single-axis Acoustic Levitator SAL ${ }^{\mathrm{TM}}$, by Materials Development, Inc (MDI), constituted by a levitation device, with two transducers placed on a vertical axis, generating two acoustic waves of $22 \mathrm{KHz}$ has been combined with two spectrometers for collecting spectra in a wide wave-vector range.

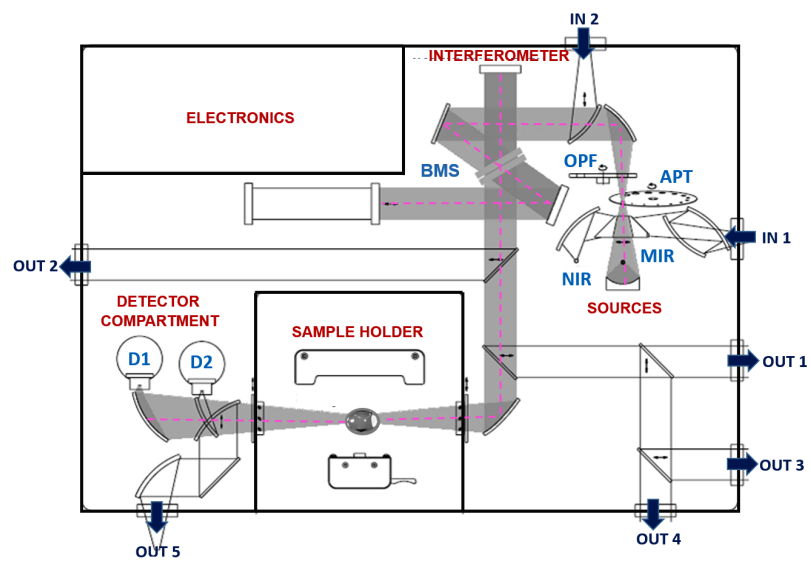

Fig. 2. Scheme of optical beam path in the Bruker Vertex 70V IR spectrometer from source to detectors. NIR, MIR: Beamsplitters; APT: Aperture wheel; OPF: Optical filter wheel; BMS: Interferometer beamsplitter; D1, D2: detectors; IN: IR beam inlet ports and OUT: IR beam outlet ports.

More precisely, Raman spectra were collected by the Horiba Jobin Yvon T64000 spectrometer, which works with a He-Ne laser with a mean source power of $60 \mathrm{~mW}$ at a wavelength of $632.8 \mathrm{~nm}$. As far as the IR spectra are concerned, a Vertex 70v by Bruker spectrometer, with a resolution of $4 \mathrm{~cm}^{-1}$ using an average of 128 scans and a spectral range of $400 \div 4000 \mathrm{~cm}^{-1}$ was employed. Fig. 1 and Fig. 2 show the laser beam and the path in the Raman and IR spectrometers respectively.

Fig. 3 reports the acoustic levitation system. It has dimensions of $30 \times 45 \times 60 \mathrm{~cm}$, a total weight of $30 \mathrm{Kg}$, works at sound pressure levels lower than $160 \mathrm{~dB}$ and has a transducers distance of $15 \mathrm{~cm}$.

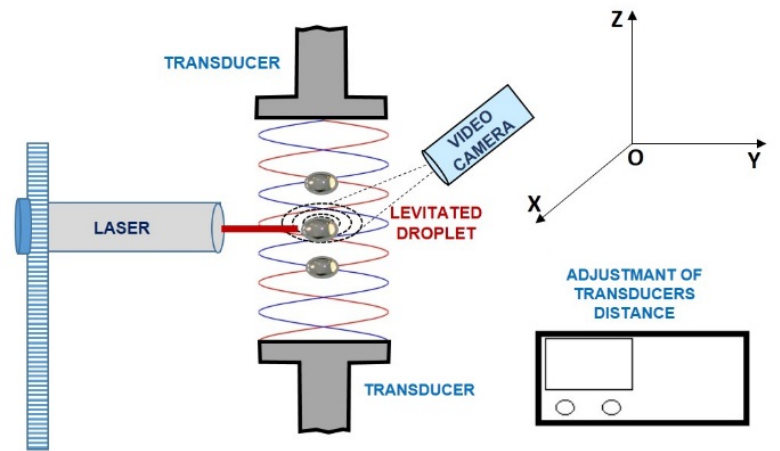

Fig. 3. Single-axis Acoustic Levitator (SAL) system. A direct droplet diameter evaluation was performed by a video camera and a laser pointer; the diameter was also evaluated by an indirect measure through the $\mathrm{OH} / \mathrm{CH}$ band area ratio analysis of collected Raman and Infrared spectra. 


\section{Results and discussion}

For testing the $\mathrm{D}^{2}$ versus time law, a direct measure was performed by means of a video camera and a laser pointer provided with a micrometric screw for an exposition time of $1 \mu \mathrm{s}$. In addition, an indirect diameter evaluation was performed by the analysis of the $\mathrm{OH} / \mathrm{CH}$ band area ratio of the solution spectra collected as a function of time. The $\mathrm{D}^{2}$-law predicts that the square of the droplet diameter decreases linearly with time, in the initial stage. Few important assumptions must be considered for the droplet in suspension: i) heat and mass transfer between liquid and gas phase are diffusion controlled; ii) droplet spherical symmetry; iii) single phase component; iv) no thermal radiation effects take place; v) constant and uniform temperature. For the mass flux of vapour leaving the droplet surface, $\dot{m}_{v}$ :

$$
\dot{m}_{v}=\pi D \rho_{v} D_{g} S h B_{M}
$$

where $D$ is the droplet diameter, $\rho_{v}$ is the vapor density, $D_{g}$ is the diffusion coefficient of the gas, $S h$ is the Sherwood number for mass transfer, and $B_{M}$ represents the mass transfer Spalding number [83-84]. For the rate change of liquid droplet mass it is:

$$
\dot{m}_{d}=-\rho_{d} \frac{d V}{d t}
$$

$\rho_{d}$ is the density of the droplet, and $\frac{d V}{d t}$ is the rate of the

droplet volume change. Considering that $\dot{m}_{v}=-\dot{m}_{d}$, it

is possible to obtain the equation for the diameter:

$$
\frac{\mathrm{dD}^{2}}{\mathrm{dt}}=-4 \frac{\rho_{\mathrm{g}}}{\rho_{\mathrm{d}}} \mathrm{D}_{\mathrm{g}} \operatorname{Sh} \ln \left(1+\mathrm{B}_{\mathrm{M}}\right)
$$

where $\rho_{g}$ is the density of the gas; for diffusion controlled evaporation the Sherwood number $S h$ takes the value of 2 :

$$
\frac{\mathrm{dD}^{2}}{\mathrm{dt}}=-8 \frac{\rho_{\mathrm{g}}}{\rho_{\mathrm{d}}} \mathrm{D}_{\mathrm{g}} \ln \left(1+\mathrm{B}_{\mathrm{M}}\right)
$$

the integration of this equation at $t=0$ gives the $\mathrm{D}^{2}$-law that describes the time evolution of droplet surface of pure liquid:

$$
D^{2}=D_{0}^{2}-\beta t
$$

where $\beta$ is the evaporation rate coefficient:

$$
\beta=8 \frac{\rho_{g}}{\rho_{d}} D_{g} \ln \left(1+B_{M}\right)
$$

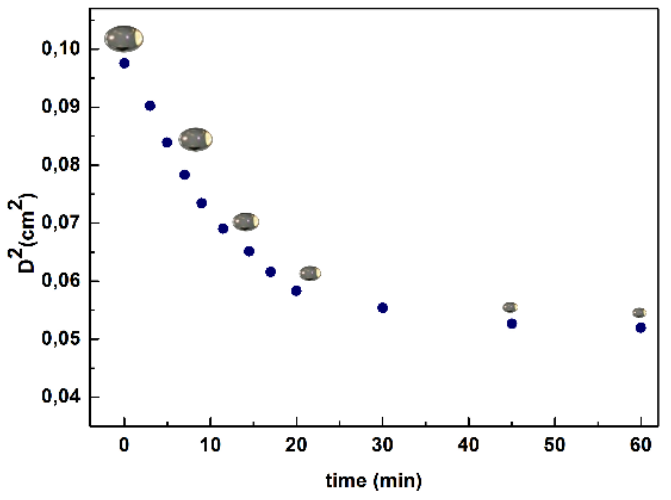

Fig. 4. Measured $D^{2}$-Law as a function of time. Droplets: diameter values as evaluated by means of the video camera. Blue dots: diameter values as evaluated by the analysis of the $\mathrm{OH} / \mathrm{CH}$ band area ratio of the solution spectra. As it can be seen $\mathrm{D}^{2}$ versus $t$ decreases linearly in in the initial stage.

Fig. 4 reports the $\mathrm{D}^{2}$ data, droplets as a function of time, obtained by a direct measure with a video camera. As it can be seen, $\mathrm{D}^{2}$ vs $t$ follows a linear trend for about 20 minutes, reaching a plateau at longer time.

This result shows how trehalose is able to avoid total water evaporation since a percentage of water is strongly bonded with the disaccharide. Such a property plays a key role in bioprotection.

Another analysis that allows to extract information on the drying process of aqueous solution of trehalose is to consider the intramolecular region of spectra. In particular, due to the presence of an isosbestic point in the IR spectra and of an isoskedastic point in the Raman spectra, it is possible to decompose the spectra into two contributes: an "open" contribution, centered around at $3210 \mathrm{~cm}^{-1}$ and a "closed" contribution, centered around at $3420 \mathrm{~cm}^{-1}$.

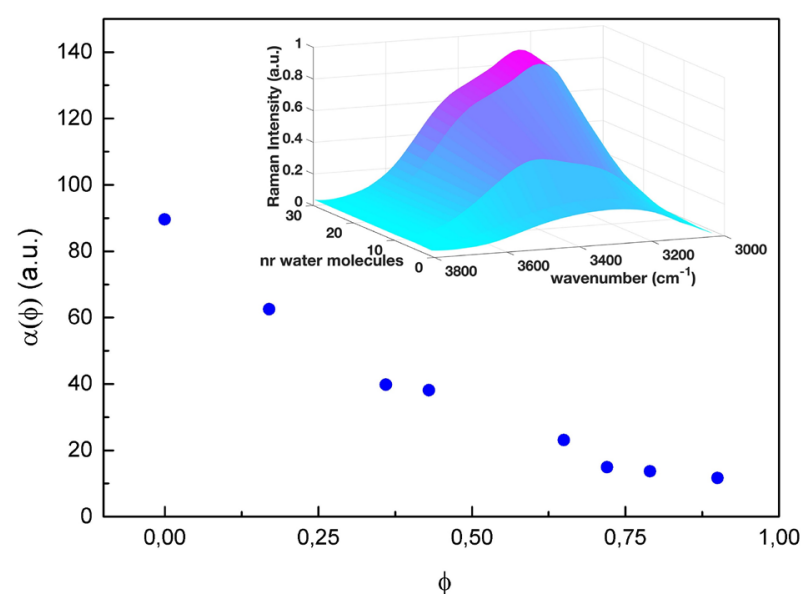

Fig. 5. Behavior of the Raman open area contribution as a function of trehalose weight fraction, i.e. $\phi=$ (grams of trehalose)/(grams of trehalose + grams of $\mathrm{H} 2 \mathrm{O}$ ), is reported. In the insert, 3D levitated Raman spectra of trehalose aqueous solutions as a function of number of water molecules and wavenumber are reported. 
Fig. 5 shows the behavior of the total area, sum of the two contributions, as a function of concentration of trehalose, where $\phi$ is the trehalose weight fraction, i.e. $\phi$ $=$ (grams of trehalose) $/$ (grams of trehalose + grams of $\mathrm{H}_{2} \mathrm{O}$ ). In the insert, the 3D levitated Raman spectra of trehalose aqueous solutions as a function of number of water molecules and wavenumber at $\mathrm{T}=25^{\circ} \mathrm{C}$ are reported.

Fig. 6 reports the behavior of the open area contribution as a function of time is reported. In the insert, the 3D levitated IR spectra of trehalose aqueous solutions as a function time and wavenumber at $\mathrm{T}=25^{\circ} \mathrm{C}$ are reported.

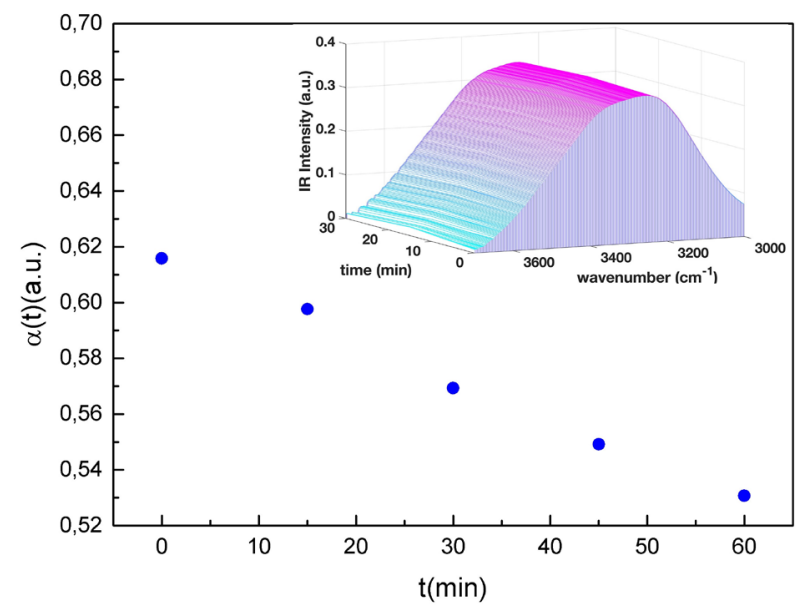

Fig. 6. Behaviour of the open area contribution of levitated IR spectra as a function of time. In the insert, the 3D levitated IR spectra of trehalose aqueous solutions as a function time and wavenumber at $\mathrm{T}=20^{\circ} \mathrm{C}$ are reported.

The mathematical procedure to evaluate concentration is a mapping of the $\mathrm{OH} / \mathrm{CH}$ band area ratio as a function of different solution concentration values. In particular a $\mathrm{OH} / \mathrm{CH}$ band area ratio for the acoustically levitated droplets for different levitation time was evaluated starting from the measured IR spectra; then, by using density versus concentration data, it was possible to determine, in an independent way, the droplet diameter evolution as a function of time. In such a way it is possible to test the $\mathrm{D}^{2}$ law of the drying process theoretical model. Fig. 4 reports the $\mathrm{D}^{2}$ data, blue dots as a function of time. Again $\mathrm{D}^{2} \mathrm{vs} t$ follows a linear trend for about 20 minutes. Therefore the experimental results show that the validity of the drying theoretical model and of the adopted approaches.

\section{Conclusions}

In this work, the results of an experimental study, where laser techniques are applied to acoustically levitated droplets of trehalose aqueous solutions are reported. The study of trehalose is particularly important for a better understanding of extremophiles, organisms that can survive in harsh conditions. It is shown how acoustic levitation, combined with spectroscopic techniques, allows to explore a wide disaccharide concentration range and to test the dependence of the diameter law as a function of lag time, i.e. $\mathrm{D}^{2}$ versus time. The aim is to perform Raman and IR spectroscopic analyses and to test the validity of the diameter law. By these analyses, it emerges that the behaviour of $\mathrm{D}^{2}$ vs $t$ follows a linear trend for about 20 minutes, reaching then a plateau at longer time. The result is confirmed by the analysis of the intramolecular region, showing that trehalose is able to avoid total water evaporation, this property being essential forable to survive under extreme environmental conditions thanks to the synthesis of trehalose. These extreme environments are characterized, for example, by high aridity, very hot and low temperatures, high salinity and high values of $\mathrm{pH}$. Just to report some example, the Atacama Desert (Chile, USA), is one the most arid place on Earth, with a year average rain fall lower than 0.08 $\mathrm{mm}$, where it is possible to find Selaginella lepidophylla; such a plant adapts itself to a condition of prolonged òt in this environment.

Another extreme environment is furnished by the Death Valley (USA), this region holding the record for the World highest air temperature equal tqo $56.7^{\circ} \mathrm{C}$ in July 1913; concerning the extremophiles that are present in this extreme environment, it is possible to mention Bacillus Vallismortis which ferments trehalose.

The obtained results put into evidence that trehalose molecules are capable to strongly bond themselves to water molecules, so avoiding water evaporation under high temperature and drought conditions.

This research was supported by University of Messina Research \& Mobility 2016 Project (project code RES_AND_MOB_2016_TORRISI).

\section{References}

1. H.T. Mohamed, V. Untereiner, G.D. Sockalingum GD, et al. Glycoconj J. 34, 309 (2017)

2. C. Branca, S. Magazù, G. Maisano, et al. J. Phys. Condens. Matter 10, 10141 (1998)

3. M. I. Santos, E. Gerbino, E. Tymczyszyn et al. Foods, 4, 283 (2015)

4. C. Branca, S. Magazu, G. Maisano et al. J. Phys. Cond. Matter 11, 3823 (1999)

5. S.Y. Lin, M. J. Li and W.T. Cheng, Spect. 21, 1 (2007)

6. L. Hennet, I. Pozdnyakova, V. Cristiglio et al. J. Phys. Condens. Matter 19, 455210 (2007)

7. D. L. Hennet, L., Cristiglio, V., Kozaily, et al., Eur. Phys. J. Spec. Top. 196, 151 (2011)

8. N. Acharya, S. A. Acharya, V. N. Kanika et al. Biochem. J. 405, 503 (2007)

9. F. Aliotta, M.E. Fontanella, S. Magazù, U. Wanderlingh, Prog. Colloid Polym. Sci. 84,483 (1991)

10. A. Apicella, B. Cappello, M. A. Del Nobile, et al. Biomaterials 14, 83 (1993)

11. B. Arumugam, V., Akalya, A., Rajasekaran, J. F., Balakrishnan, J. Polym. Mater. 17, 371 (2000) 
12. G. Mathiak, J. Brillo, I. Egry, et al. Microgravity Sci. Technol. 18, 67 (2006)

13. G. Mathiak, I. Egry, L. Hennet, et al. in Int. J. Thermophys. 26,1151 (2005),

14. A. Ashkin, J. M. Dziedzic, J. E. Bjorkholm, and S. Chu, Opt. Lett. 11, 288 (1986)

15. W. J. K. R. Benmore, C.J., Phys. Rev. X 1, 01104 (2011)

16. J. K. R. DeVos, J. K., Hampton, D. S., Merkley et al., Int. J. Microgravity Sci. Appl. 9, 146 (1992)

17. J. W. E. Drewitt, L. Hennet, A. Zeidler et al., Phys. Rev. Lett. 109, 235501 (2012)

18. C. J. Benmore, J. K. R. Weber, A. N. Tailor et al., J. Pharm. Sci. 102, 1290 (2013)

19. P. C. Biswas, A., Weber J.K.R., Nordine, J. Mater. Res. 10, 1823 (1995)

20. M. Li, W., Kim, Y., Lia, J., Lee, Soft Matter 10, $5231(2014)$

21. B. Jonsson, B. Lindman, and K. Holmberg, IEEE Electr. Insul. Mag. 14, 42 (1998)

22. F. Kozaily, J., Hennet, L., Fischer et al. Phys. Status Solidi Curr. Top. Solid State Phys. 8, 3155 (2011)

23. S. Cerveny, Á. Alegría, and J. Colmenero, Phys. Rev. E 77, 031803 (2008)

24. S. Magazù, F. Migliardo, F. Affouard et al. J. Chem. Phys. 132, 184512 (2010)

25. S. Magazù, F. Migliardo, and A. Benedetto, Rev. Sci. Instrum. 82, 184512 (2011)

26. S. L. Bradbury, W. B. Jakoby, Proc. Natl. Acad. Sci. U. S. A. 69, 2373 (1972)

27. P.-O. I. Cuello, G. J., Cristiglio, V., Hennet, L., in J. Phys. Conf. Ser. 549, 012002 (2014)

28. I. Egry, a. Diefenbach, W. Dreier, and J. Piller, Int. J. Thermophys. 22, 569 (2001)

29. A. Braun, P. C. Stenger, H. E. Warriner, J et al. Biophys. J. 93, 123 (2007)

30. S. Magazù, E. Calabrò, M. T. Caccamo, and A. Cannuli, Curr. Chem. Biol. 10, (2016)

31. R. A. Krishnan, S., Nordine, P. C., Weber, J. K. R., Schiffman, High Temp. Sci. 31, 45 (1991)

32. S. L. Bradbury and W. B. Jakoby, Proc. Natl. Acad. Sci. U. S. A. 69, 2373 (1972)

33. M. Li, W., Kim, Y., Lia, J., Lee, Soft Matter 10, 5231 (2014)

34. S. Magazù, Phys. B 226, 92 (1996)

35. S. Magazù, J. Mol. Struct. 523, 47 (2000).

36. K. Venkatramanan, Int. Rev. Chem. Eng. 3, 308 (2011)

37. L. C. P. Wang, T. G., Anilkumar, A.V., J. Fluid Mech. 308, 1 (1996)

38. J. K. R. Weber, S. Krishnan, S. Ansell, A. A. . Hixson, and P. P. C. Nordine, Phys. Rev. Lett. 84, 3622 (2000).

39. R. J. K. Weber, C. J. Benmore, S. K. Tumber et al. Eur. Biophys. J. 41, 397 (2012)

40. J. K. R. Weber, C. A. Rey, J. Neuefeind, and C. J. Benmore, Rev. Sci. Instrum. 80, (2009)

41. R. J. K. Weber, C. J. Benmore, S. K. Tumber et al. Eur. Biophys. J. 41, 397 (2012)
42. M. T. Caccamo, A. Cannuli, E. Calabrò, and S. Magazù, IOP Conf. Ser.: Mater. Sci. Eng. 199 012119 (2017)

43. S. Magazù, F. Migliardo, and M. T. Caccamo, Adv. Mater. Sci. Eng. 2013, (2013)

44. F. Migliardo, M. T. Caccamo, and S. Magazù, J. Non. Cryst. Solids 378, 144 (2013)

45. F. Migliardo, S. Magazù, and M. T. Caccamo, J. Mol. Struct. 1048, 261 (2013)

46. F. Migliardo, S. Magazù, M.T. Caccamo, Food Biophys. 9, 99 (2014)

47. S. Magazù, F. Migliardo, M. T. Caccamo, 2012, J. Phys. Chem. B, 116, 9417 (2012).

48. W. K. Rhim, S. K. Chung, D. Barber et al. Rev. Sci. Instrum. 64, 2961 (1993).

49. B. Cappello, M. A. Del Nobile, M. I. La Rotonda et al. Farmaco 49, 809 (1994).

50. T. K. Rostovtseva, E. M. Nestorovich, S. M. Bezrukov, Biophys. J. 82, 160 (2002).

51. O. Smith, G.D., Bedrov, D. Borodin, J. Am. Chem. Soc. 122, 9548 (2000).

52. J. J. Towey, K. Soper, L. Dougan, Phys. Chem. Chem. Phys. 13, 9397 (2011a).

53. S. Condello, E. Calabrò, D. Caccamo et al. J., Amino Acids, 42: 775(2012)

54. Magazù, S., Migliardo, F., Benedetto, et al. in Dynamics of Biological Macromolecules by Neutron Scattering, 22 (2011)

55. Branca, C., Maccarrone, S., Magazù, et al., J. Chem. Phys. 122, 174513 (2005)

56. Branca, C., Magazù, S., Migliardo et al., Physica A: Statistical Mechanics and its Applications, 304, 314 (2002)

57. B. Varga, F. Migliardo, E. Takacs et al. Chem. Phys. 345, 250 (2008).

58. R. Chelli, P. Procacci, G. Cardini et al. Phys. Chem. Chem. Phys. 1, 879 (1999)

59. J. Chen, S. K. Spear, J. G. Huddleston et al. Green Chem. 7, 64 (2005)

60. P. J. Flory, Cornell Univ. Press. Ithaca, New York 399 (1953).

61. A. K. Gangopadhyay, G. W. Lee, K. F. Kelton et al., Rev. Sci. Instrum. 76, (2005).

62. P. Gonzalez-Tello, F. Camacho, G. Blazquez, J. Chem. Eng. Data 39, 611 (1994).

63. R. Grandori, I. Matecko, P. Mayr, N. Muller, J. Mass Spectrom. 36, 918 (2001).

64. C. Granier, J. Potard, in 6th Eur. Symp. Microgravity. Bordeaux, Fr. ESA SP-256 421 (1987)

65. S. A. Hu, T., Manjula, B. N.; Li et al. Biochem. J. 402, 143 (2007)

66. G. Jacobs, I. Egry, K. Maier et al. Rev. Sci. Instrum. 67, 3683 (1996)

67. B. Jonsson, B. Lindman, and K. Holmberg, IEEE Electr. Insul. Mag. 14, 42 (1998)

68. F. Kozaily, J., Hennet, L., Fischer, H.E. et al. Phys. Status Solidi Curr. Top. Solid State Phys. 8, 3155 (2011)

69. Marchese, N., Cannuli, A., Caccamo, M.T. et al. Biochim. Biophys. Acta - General Subjects, 1861, 3661(2017 
70. S. Magazù, F. Migliardo, A. Benedetto, et al. J. Non. Cryst. Solids, 357, 664 (2011)

71. D. Barreca, G. Laganà, S. Ficarra et al. Biophys. Chem. 147, 146 (2010)

72. S. E. Pagnotta, M. A. Ricci, F. Bruni, S. McLain, and S. Magazù, Chem. Phys. 345, 159 (2008)

73. P. Ballone, M. Marchi, C. Branca et al., J. Phys. Chem. B 104, 6313 (2000)

74. S. Magazù, G. Maisano, H. D. Middendorf et al. J. Phys. Chem. B 102, 2060 (1998).

75. S. Magazù, G. Maisano, P. Migliardo et al. J. Chem. Phys. 109, 1170 (1998)

76. M. T. Caccamo, G. Castorina, F. Colombo, V., Insinga, E. Maiorana, S. Magazù, Atmosph. Res. 198, 22 (2017)

77. M. T. Caccamo, S. Magazù, Spectrosc. Lett. 50, 130 (2017).

78. R. Patil, Procedia Comp. Sc. 54, 849 (2015)

79. M. Srivastava, C. Lindsay Anderson, Jack H. Freed IEEE Access. 4, 3862 (2016)

80. M. T. Caccamo, S. Magazù, Vib. Spectrosc. 85, 222 (2016).

81. M.T. Caccamo, S. Magazù, Appl. Spectrosc. 71, 401 (2017).

82. M.T. Caccamo, S. Magazù, Polym. Testing, 62, 311(2017)

83. A. N. Hayhurst, M. S. Parmar, Combustion and Flame 130, 361 (2002)

84. Peiyong Ni, Appl. Mathem. Modell. 34, 2370 (2010) 